\title{
Exposure to sediment enhances primary acquisition of Symbiodinium by asymbiotic coral larvae
}

\author{
Lisa M. Adams ${ }^{1, *}$, Vivian R. Cumbo ${ }^{2}$, Misaki Takabayashi ${ }^{1}$ \\ ${ }^{1}$ Marine Science Department, University of Hawai'i at Hilo, 200 West Kawili St., Hilo, Hawai'i 96720, USA \\ ${ }^{2}$ School of Marine and Tropical Biology, James Cook University, Townsville, Queensland 4811, Australia
}

\begin{abstract}
Many symbiotic marine invertebrates acquire free-living Symbiodinium from the environment. Abundance and diversity of free-living Symbiodinium could influence recovery from bleaching, resilience, and the long-term adaptation of host organisms. Although free-living Symbiodinium have been detected in the water column and substrates of coral reefs, their diversity and availability to the hosts are poorly understood. Tank experiments were conducted to test whether asymbiotic coral larvae of Acropora monticulosa acquired free-living Symbiodinium from the water column or sediment to become symbiotic. Treatments included filtered $(0.22 \mu \mathrm{m})$ seawater (FSW), unfiltered seawater (SW), FSW and sediment, and SW and sediment. Our results showed that greater proportions of larvae in sediment-containing treatments acquired Symbiodinium earlier and had greater in hospite Symbiodinium densities when compared to seawater-only treatments. Additionally, clade A Symbiodinium was only recovered in the larvae from the sediment-containing treatments, whereas clades B and C were recovered from all treatments. Differences in distribution, abundance, replication and motility patterns of Symbiodinium, as well as larval behavior, may have contributed to the observed differences between uptake from the sediment and the water column. However, our results suggest that the sediment may represent an important source of free-living Symbiodinium available for uptake during primary acquisition by coral larvae.
\end{abstract}

KEY WORDS: Free-living Symbiodinium · Acquisition · Coral larvae · Reef sediment · Water column • Acropora monticulosa

Resale or republication not permitted without written consent of the publisher

\section{INTRODUCTION}

An array of foraminiferans, mollusks, and cnidarians benefit from mutualistic symbioses with dinoflagellates of the genus Symbiodinium, commonly known as zooxanthellae. Genetic analyses have divided the genus Symbiodinium into 8 clades (A through H) and numerous subclades and strains (Pochon et al. 2006, Sampayo et al. 2007). The type of Symbiodinium in hospite can influence the biological processes of the invertebrate host such as growth and reproduction (Kinzie \& Chee 1979, Fitt 1985, Little et al. 2004). Ultimately, the dinoflagellate symbiont plays a crucial role in determining the fate of the host throughout its lifetime and host adaptability under variable environmental conditions over generations. Thus the fitness of the host may be enhanced by associating with diverse
Symbiodinium types and/or those best adapted to the local environment (Toller et al. 2001, Berkelmans \& van Oppen 2006).

Invertebrate hosts may obtain Symbiodinium 'vertically,' from parent to offspring, or 'horizontally,' from the environment surrounding them (Harrison \& Wallace 1990). Horizontal acquisition is, debatably, beneficial to hosts, giving each generation of hosts an opportunity to associate with diverse types or a particular type of Symbiodinium that is adaptive to the local environmental conditions (Buddemeier \& Fautin 1993, Glynn 1993, Brown 1997, Kinzie et al. 2001, Douglas 2003, Fautin \& Buddemeier 2004). Dominance of a new symbiont type may be a disadvantage to the host, leading to decreased health, growth or reproduction (Little et al. 2004, Stat et al. 2008). However if the new dominant symbiont enables survival of the host through 
stress events such as bleaching then this mode may be advantageous in the long-term life history of the species. Furthermore, adults of some host species may be able to acquire a new strain of Symbiodinium through secondary acquisition following stress events, such as bleaching (Kinzie et al. 2001). Despite its apparent adaptive advantages, secondary acquisition in scleractinian corals has not been observed, possibly due to experimental limitations. This lack of evidence has lead investigators to suggest that hosts shuffling proportions of different Symbiodinium strains already in hospite is the predominant mode of physiological adaptation in scleractinian corals (Berkelmans \& van Oppen 2006). If this is the case, then primary acquisition of Symbiodinium strains is critically important in the entire life history of these hosts. Resilience of symbiotic reef organisms, like corals, may thus be especially reliant upon the symbiont types specifically involved in primary acquisition (Baird et al. 2007).

Given the dependence of reef invertebrates on environmental pools of Symbiodinium, it is imperative to understand the diversity and ecology of free-living Symbiodinium and their interactions with potential hosts. Free-living Symbiodinium have been identified in the water column and substrates of coral reefs (Carlos et al. 1999, Coffroth et al. 2006, Koike et al. 2007, Hirose et al. 2008, Littman et al. 2008, Manning \& Gates 2008, Porto et al. 2008). To date the diversity of free-living Symbiodinium and their availability for uptake by host organisms have been poorly characterized. In hospite studies have utilized settled coral recruits to investigate primary acquisition of Symbiodinium (Kinzie et al. 2001, Coffroth et al. 2006). However, settlement materials may influence results if free-living Symbiodinium are attracted to artificial substrates. Moreover, acquisition could occur in larvae before metamorphosis to the juvenile polyp stage (Schwarz et al. 1999, Weis et al. 2001, RodriguezLanetty et al. 2004, Marlow \& Martindale 2007). In the present study, we tested whether asymbiotic coral larvae of Acropora monticulosa preferentially acquired free-living Symbiodinium from the water column or sediment.

\section{MATERIALS AND METHODS}

Collection. Six mature colonies of Acropora monticulosa were collected from the southwest side of the island of Akajima at Sakubaru, Japan, and taken to the Akajima Marine Science Laboratory (AMSL). Colonies were maintained in tanks with running seawater until spawning time, where they were isolated in an aquarium and allowed to spawn. Spawning occurred between 23:00 and 23:30 h on August 4, 2007. Eggs and sperm were collected, allowed to fertilize for
$30 \mathrm{~min}$ and then reared in filtered seawater $(0.22 \mu \mathrm{m})$ until larvae were ready for transport. The $2 \mathrm{~d}$ old asymbiotic larvae that were swimming and had developed a mouth were transported in filtered seawater $(0.22 \mu \mathrm{m})$ to the Sesoko Tropical Biosphere Research Center, Okinawa, Japan. These larvae were added to experimental treatments on the third day after spawning. Additionally, fragments from 10 adult colonies of $A$. monticulosa were also collected at Sakubaru from a depth of 1 to $4 \mathrm{~m}$ for DNA analysis of symbiont type to compare with those acquired by larvae.

Acquisition experiment. Four treatments, each with 3 replicates (12 aquaria total), were used to identify the source of Symbiodinium that were acquired by asymbiotic Acropora monticulosa larvae in a tank experiment: (1) filtered $(0.22 \mu \mathrm{m})$ seawater (FSW), (2) unfiltered seawater (SW), (3) natural sediment and filtered seawater (FSW \& SED), and (4) natural sediment with unfiltered seawater (SW \& SED). Seawater and sediment used in treatment aquaria were collected from the reef immediately south of Sesoko Station between 15:00 and 17:00 h on August 7, 2007 (Day 0). Surface seawater was collected from directly over the reef at $<1 \mathrm{~m}$ depth. Sediment was collected using a $50 \mathrm{ml}$ falcon tube by gently collecting the top, oxic layer (determined by coloration; gray or black sediment indicating anoxic conditions) of sediment. All sediment samples were collected from the reef at the 2 to $5 \mathrm{~m}$ depth. Aquaria were approximately $1.5 \mathrm{l}$ in volume and contained $1.0 \mathrm{l}$ of seawater and, when appropriate, $100 \mathrm{ml}$ of sediment. Aquaria were left alone for $6 \mathrm{~h}$ to allow sediment to settle and temperatures of seawater to equilibrate with room temperature $\left(27^{\circ} \mathrm{C}\right)$. On Day 0, 100 larvae were added to each aquarium. Aquaria were maintained at $27^{\circ} \mathrm{C}$ and exposed to an average of 60 to $80 \mu \mathrm{mol}$ photons $\mathrm{m}^{-2} \mathrm{~s}^{-1}$ of light on a $12 \mathrm{~h}$ light: dark cycle. Gentle airflow was also applied to all aquaria, producing minimal water circulation.

At each census (3, 6, and $12 \mathrm{~d}$ after initiation), 10 larvae from each aquarium were surveyed for the presence or absence of Symbiodinium. Larvae were washed in filtered seawater $(0.22 \mu \mathrm{m})$, mounted onto glass slides with cover slips, and viewed under an epifluorescent microscope (Nikon Microphot-FXA). With excitation of 450 to $490 \mathrm{~nm}$ and filter of 510 to $550 \mathrm{~nm}$ (B2 filter set), the larvae fluoresced green and the Symbiodinium were bright red due to chlorophyll a ( $\mathrm{chl}$ a), making the presence of symbionts very easy to identify. Cover slips were placed gently over the larvae, flattening without rupturing them, into a 1-dimensional plane to more accurately count Symbiodinium in hospite. For each larva, acquisition status (presence or absence of Symbiodinium) and the number of resident Symbiodinium were recorded.

Statistical analysis. The Day 6 data were used in statistical analysis of Symbiodinium densities because 
it was the only day that had density data for all treatments, and essentially represented the end of the experiment. The filtered seawater and seawater treatments were the only ones for which data were available on Day 12; both the proportion of symbiotic larvae and Symbiodinium densities per larva in the seawater treatment were not significantly different $(p>0.05)$ between Day 6 and Day 12. Logistic regression analysis was performed to compare the proportions of symbiotic larvae among treatments. A nested ANOVA was used to test whether treatments or replicate aquaria had an effect on Symbiodinium densities in the larvae; replicated aquaria were nested within treatments. A Tukey's multiple comparisons test was used to pinpoint the differences in in hospite densities of larvae between treatments. The Symbiodinium densities in the larvae were transformed $[\log ($ density +1$)]$ to normalize the data for analysis. Density data included zero values from larvae that did not acquire Symbiodinium. All statistical analyses were performed in S-Plus ${ }^{\circledR} 8.0$ for Windows (Insightful).

DNA analysis. The clade of Symbiodinium residing in larvae was identified genetically. At the end of the acquisition experiment above, remaining larvae from each aquarium were washed in filtered seawater $(0.22 \mu \mathrm{m})$ and pooled for DNA extraction. The larval and adult coral samples were incubated in $300 \mu \mathrm{l}$ of a guanidinium lysis buffer (4 M guanidinium isothiocyanate, 0.05 M Tris pH 7.6, 0.01 M EDTA, 0.07 M Sarkosyl, $\beta$-mercaptoethanol $1 \%$ v/v) (Pochon et al. 2001) for 5 to $17 \mathrm{~d}$ at room temperature and then at $72^{\circ} \mathrm{C}$ for $10 \mathrm{~min}$ before being centrifuged for $5 \mathrm{~min}$ at $16060 \times g$ at room temperature. DNA from the resulting supernatant was precipitated with $100 \%$ isopropanol, pelleted, rinsed with $70 \% \mathrm{EtOH}$, dried and resuspended in 0.01 M Tris-HCL pH 8. PCR amplifications were performed using the Symbiodinium-specific primers '23SHYPERUP' and '23SHYPERDN' for the hyper-variable region of Domain $\mathrm{V}$ in the large subunit of the chloroplast ribosomal array (cp23S-HVR) (Santos et al. 2003). PCRs were carried out on an ABI 2720 thermal cycler under the following conditions: initial denaturing period of $2 \mathrm{~min}$ at $94^{\circ} \mathrm{C}, 50$ cycles consisting of $94^{\circ} \mathrm{C}$ for $30 \mathrm{~s}, 55^{\circ} \mathrm{C}$ for $1 \mathrm{~min}, 72^{\circ} \mathrm{C}$ for $1 \mathrm{~min} 15 \mathrm{~s}$, and a final extension period of $7 \mathrm{~min}$ at $72^{\circ} \mathrm{C}$. Amplification products were difficult to obtain and optimization of the PCR required the cycle number to increase from 36 cycles to 50 cycles as recommended by Palumbi et al. (1991). Amplification products were separated by cloning with the pGEM ${ }^{\circledR}$-T Easy Vector System II (Promega) according to the manufacturer's protocol. The resulting products were sequenced using an ABI 3730XL capillary-based DNA sequencer (Applied Biosciences) at the Advanced Studies in Genomics, Proteomics and Bioinformatics Sequencing Facility at
University of Hawai'i at Manoa. A total of 19 to 25 clones per aquarium sample and 1 to 10 clones per adult coral colony were sequenced. Chromatograms of sequenced clones were manually checked and aligned with Sequencher 4.5 (Gene Codes). True alleles were determined by having multiple sequences. A few alleles were represented by only 1 sequence and had only 1 base pair different from the majority of sequences; these alleles were deemed the result of PCR, cloning or sequencing error and discarded. The clade identity of each true allele was determined by a positive match (100\% sequence identity) with genotyped sequences in GenBank database using the BLAST analyses (Altschul et al. 1990).

\section{RESULTS}

Larvae of both sediment-containing treatments (FSW \& SED and SW \& SED) acquired Symbiodinium earlier and in higher densities than those in treatments without sediment (Fig. 1). Data shows that treatments
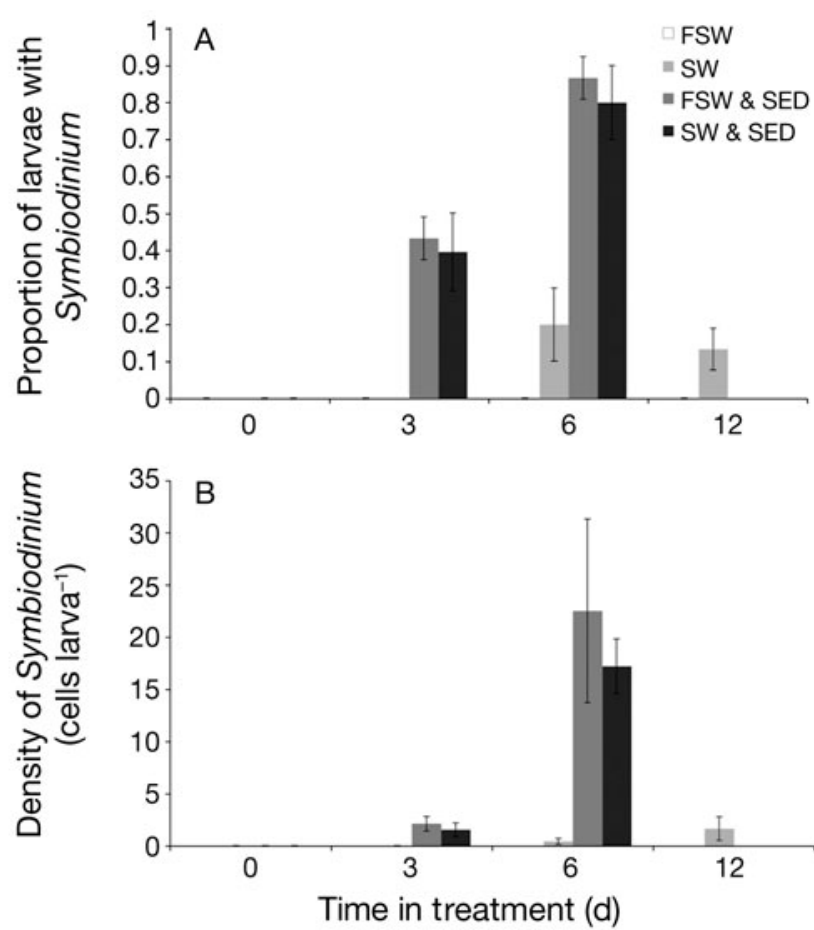

Fig. 1. Acropora monticulosa. (A) Proportion of larvae (mean \pm $\mathrm{SD}$ ) that acquired Symbiodinium and (B) in hospite Symbiodinium densities (mean $\pm \mathrm{SE}$ ) within larvae from each treatment at each survey day. (FSW: filtered seawater; SW: unfiltered seawater; SED: sediment). All larvae from the control aquaria (FSW) remained asymbiotic throughout the duration of the experiment. No acquisition was seen in larvae of the seawater treatment (SW) on Day 3. Supply of larvae from treatments with sediment was depleted after Day 6; thus no data were available for these treatments on Day 12 
had significantly affected the proportion of larvae containing Symbiodinium $(\mathrm{p}<0.001)$. Throughout the experiment, Symbiodinium densities in larvae of treatments without sediment, $2.2 \pm 0.27$ cells per larva (mean $\pm \mathrm{SE})$, were significantly lower $\left(\mathrm{F}=219.15_{3,4}, \mathrm{p}<\right.$ 0.001 ) than those of treatments with sediment, $23.77 \pm$ 4.09 cells per larva. Symbiodinium densities in larvae of replicates of each treatment aquaria were not significantly different from each other $\left(\mathrm{F}=0.21_{4,112}, \mathrm{p}=0.93\right)$.

Clade A Symbiodinium was only recovered in the larvae from the sediment-containing treatments. DNA sequence analyses revealed that larvae acquired clades B and C Symbiodinium from the water column, and clades A, B and C from the sediment; whereas adults of the same species harbored clade $C$ (Table 1) (GenBank accession numbers: EU514958, EU514976, EU515077 and EU515094). Four alleles of Symbiodinium were detected in this study and are referred to as A196, A192, B182, C178, as the appropriate nomenclature for cp23S-rDNA domain V sequences (Santos et al. 2003).

Larvae lost due to mortality or settlement averaged $36 \pm 4.36$ larvae (mean $\pm \mathrm{SD}$ ) in FSW treatments, $67 \pm$ 4.73 larvae in SW treatments, $53 \pm 20.6$ larvae in FSW \& SED treatments and $66 \pm 4.72$ larvae in SW \& SED treatments. Mortality was likely the result of poor water quality in aquaria caused by an extended period of time with low circulation. Sediment-containing treatments were terminated at Day 6 due to insufficient number of larvae remaining as a result of mortality. The remaining larvae in these treatments were thus 'rescued' at Day 6 and maintained in filtered seawater without sediment for $6 \mathrm{~d}$ until the DNA analyses. One replicate of the SW treatment did not have excess larvae for DNA analysis due to a high amount of settlement of larvae on the sides of the aquarium.

\section{DISCUSSION}

Free-living Symbiodinium may be crucially important to the recovery, resilience, and adaptation of symbiotic invertebrates, as the future of these organisms continues to be critically compromised (HoeghGuldberg et al. 2007). The abundance and distribution of different types of free-living Symbiodinium and relative availability of Symbiodinium inhabiting different sectors of the marine environment to asymbiotic hosts have been poorly investigated to date (Coffroth et al. 2006, Koike et al. 2007, Hirose et al. 2008, Littman et al. 2008, Manning \& Gates 2008, Porto et al. 2008).

The results from our tank experiment clearly showed Symbiodinium were acquired by asymbiotic coral larvae earlier, in greater proportion, and with greater in hospite Symbiodinium densities in sedimentcontaining treatments when compared to seawater only treatments. The enhanced acquisition and in hospite densities of Symbiodinium in larvae exposed to the sediment substrate may be due to higher abundances of Symbiodinium in sediment than the water column, high replication of Symbiodinium, the relatively non-motile nature of Symbiodinium in sediment, frequent contact with the substrate by coral larvae searching for suitable settlement grounds, or any combination of these factors. In cultures, Symbiodinium tend to reside relatively still on the bottom of culture containers and periodically become mobile and move into the upper water column upon the introduction of light (Freudenthal 1962, Fitt \& Trench 1983, Crafts \& Tuliszewski 1995, Yacobovitch et al. 2004). Free-living Symbiodinium may have similar diurnal mobility patterns, which would explain the presence of Symbiodinium in the water column and in reef substrate. Few data are available for the relative

Table 1. Acropora monticulosa. Number of larvae and adult colonies from which DNA was extracted, total number of Symbiodinium cp23S-HVR sequences and the number of sequences for each allele of Symbiodinium obtained from each aquarium. Alleles are referenced by the clade and length of the cp23S-HVR region, according to Santos et al 2003. (SW: unfiltered seawater; FSW: filtered seawater; SED: sediment). No data are available for 1 replicate of SW treatment due to high settlement of larvae before collection occurred

\begin{tabular}{|c|c|c|c|c|c|c|}
\hline Treatment & $\begin{array}{l}\text { Larvae/colonies } \\
\text { extracted }\end{array}$ & $\begin{array}{c}\text { Total } \\
\text { sequences }\end{array}$ & $\begin{array}{c}\text { A196 } \\
\text { sequences }\end{array}$ & $\begin{array}{c}\text { A192 } \\
\text { sequences }\end{array}$ & $\begin{array}{c}\text { B182 } \\
\text { sequences }\end{array}$ & $\begin{array}{c}\text { C178 } \\
\text { sequences }\end{array}$ \\
\hline SW 1 & 9 & 25 & 0 & 0 & 17 & 8 \\
\hline SW 2 & 7 & 19 & 0 & 0 & 19 & 0 \\
\hline FSW \& SED 1 & 11 & 20 & 0 & 0 & 20 & 0 \\
\hline FSW \& SED 2 & 50 & 19 & 7 & 0 & 12 & 0 \\
\hline FSW \& SED 3 & 19 & 21 & 7 & 0 & 0 & 14 \\
\hline SW \& SED 1 & 19 & 23 & 3 & 20 & 0 & 0 \\
\hline SW \& SED 2 & 32 & 19 & 10 & 0 & 0 & 9 \\
\hline SW \& SED 3 & 10 & 21 & 21 & 0 & 0 & 0 \\
\hline Total & & 167 & 48 & 20 & 68 & 31 \\
\hline Adult colonies & 10 & 63 & 0 & 0 & 0 & 63 \\
\hline
\end{tabular}


abundance of Symbiodinium in sediment as compared to the water column, however reef substrate is likely the primary habitat for Symbiodinium with a higher abundance of cells in sediments at Lizard Island, Australia (Littman et al. 2008). A previous culture study has shown that the rate of acquisition of Symbiodinium is positively correlated to the densities of Symbiodinium to which a host is exposed (Kinzie et al. 2001). Likewise, the rapid uptake of Symbiodinium in sediment-containing treatments of this experiment is likely the result of higher densities of Symbiodinium in the sediment compared to the water column. Freeswimming coral larvae are less likely to be in contact with Symbiodinium in the water column because of lower chances of encounter caused by lower abundances and active motility of swimming Symbiodinium. Conversely, Symbiodinium in the sediment would be relatively still and easily accessible to larvae searching the substrate for suitable settlement grounds. Though the results of this study cannot conclusively determine if the coral larvae in aquaria acquired Symbiodinium from the sediments or water column, it is clear that the higher acquisition and densities seen in the larvae of the sediment-containing treatments was the result of Symbiodinium that originated from sediments.

An alternative - not exclusive of the above-factor for higher densities of in-hospite Symbiodinium in the sediment-containing treatments is increased nutrients. Studies have shown that nutrients can greatly enhance in hospite Symbiodinium replication (Muscatine et al. 1989, Hoegh-Guldberg 1994, Marubini \& Davies 1996, Hoegh-Guldberg \& Williamson 1999). Therefore, the increased Symbiodinium densities in larvae of sediment-containing treatments may also be attributed to high in hospite replication rates as well as a greater uptake of Symbiodinium cells. Furthermore, increased nutrients in sediments may have also influenced freeliving Symbiodinium replication and contributed to increased abundance of Symbiodinium.

In seawater-only treatments acquisition of Symbiodinium by larvae occurred later (Day 6 of the experiment) than those in sediment-containing treatments (Day 3). Though larvae of many coral species can remain competent for up to $100 \mathrm{~d}$, most reach their settlement peak by $7 \mathrm{~d}$ after spawning (Harii et al. 2002, Miller \& Mundy 2003, Nishikawa et al. 2003, Nishikawa \& Sakai 2005, Nozawa \& Harrison 2005). Moreover, population gene-flow data indirectly suggest short larval periods and recruitment being derived locally for many species of corals, with a few exceptions (Ayre \& Hughes 2000, Takabayashi et al. 2003, Nishikawa \& Sakai 2005). Therefore, the ecological significance of such late acquisition as seen in the seawater-only treatments of our study is questionable.
The larvae of seawater-only treatments in this study were 9 d old when Symbiodinium was first detected in the host. Larvae of this age in nature would most likely have settled and therefore be out of contact with the Symbiodinium in the water column.

The likelihood of larvae acquiring specific types of symbionts may also depend on differential distribution and motility patterns of free-living Symbiodinium types. In the present study, clade A Symbiodinium was acquired only by larvae in sediment-containing treatments while clades $\mathrm{B}$ and $\mathrm{C}$ were acquired by larvae in all treatments. This may be the result of intrinsic biases with PCR, cloning or number of larvae sampled for DNA analyses ( $S W=16$ larvae, FSW \& SED = 80 larvae, SW \& SED = 61 larvae). However, previous studies have found clade A Symbiodinium in the sediments but not in the water column in Hawai'i (Carlos et al. 1999), the Florida Keys (Coffroth et al. 2006), Japan (Hirose et al. 2008), and Colombia (Porto et al. 2008), despite the clades B, C, D and $\mathrm{H}$ being detected in the water column (Manning \& Gates 2008). Therefore, the present result of clade A Symbiodinium being detected in coral larvae of sediment-containing treatments is speculated to be due to differential distribution pattern of clade A compared to others. Another alternative explanation is that different types of free-living Symbiodinium possibly display varying patterns of diurnal motility between the sediment and water column, rendering clade A to be absent in the water column at the time of collection and unavailable to larvae in the seawater-only treatment. It is also possible that differences in nutrient concentrations among treatments caused different clades to dominate. Assessment of the diversity of Symbiodinium available to coral larvae in the seawater and sediments of aquaria would have enhanced our understanding of symbiont preferences or specificity of Acropora monticulosa in this study. Nonetheless, varying distribution patterns of freeliving Symbiodinium, with or without symbiont-host specificity, are expected to play an important role in determining which type of Symbiodinium establishes symbioses with hosts in early life history stages.

Initial acquisition and subsequent flexibility of coral larvae hosting different types of Symbiodinium are important for determining the success of the specific symbioses into adulthood of corals (Schwarz et al. 1999, Weis et al. 2001, Rodriguez-Lanetty et al. 2004). Our results show that Acropora monticulosa larvae are able to acquire symbiont types in 3 Symbiodinium clades, despite adults being dominated by a single symbiont type in clade C. Although all Symbiodinium types analyzed in this study are known to have successful, stable, symbioses with other invertebrates (Table 2), it is unknown if these symbionts can continue stable relationships over a long term in A. mon- 
Table 2. Summary of Symbiodinium sequences that have $100 \%$ genetic match to the Symbiodinium alleles identified in this study. GBR: Great Barrier Reef

\begin{tabular}{|c|c|c|c|c|}
\hline Allele & GenBank No. & Host species name & Collection site & Source \\
\hline \multirow[t]{4}{*}{ A196 } & EU514958 & Acropora monticulosa & Okinawa & This study \\
\hline & AY035410 & Cassiopea xamachana & Hawai'i & Santos et al. (2002) \\
\hline & AY035411 & C. xamachana & Hawai'i & Santos et al. (2002) \\
\hline & AY035412 & Tridacna gigas & Indo-Pacific & Santos et al. (2002) \\
\hline \multirow[t]{6}{*}{ A192 } & EU514976 & A. monticulosa & Okinawa & This study \\
\hline & AY035405 & C. xamachana & Hawai’i & Santos et al. (2002) \\
\hline & AY035406 & C. xamachana & Jamaica & Santos et al. (2002) \\
\hline & AY035407 & C. xamachana & Florida Keys & Santos et al. (2002) \\
\hline & AY035408 & Plexaura kuna & Panama & Santos et al. (2002) \\
\hline & AY035409 & Pseudoplexaura porosa & Panama & Santos et al. (2002) \\
\hline \multirow[t]{4}{*}{ B182 } & EU515077 & A. monticulosa & Okinawa & This study \\
\hline & AY035416 & Aiptasia pulchella & Okinawa & Santos et al. (2002) \\
\hline & AY035418 & Porites evermanni & Hawai'i & Santos et al. (2002) \\
\hline & AY055236 & Pocillopora damicornis & Hawai'i & Santos et al. (2002) \\
\hline \multirow[t]{5}{*}{ C178 } & EU515094 & A. monticulosa & Okinawa & This study \\
\hline & AJ872079 & Lobophyllia sp. & Guam & Pochon et al. (2006) \\
\hline & EF140806 & Acropora millepora & Central GBR & Cantin \& van Oppen (unpubl.) \\
\hline & EF140805 & A. millepora & South GBR & Cantin \& van Oppen (unpubl.) \\
\hline & EF140804 & Acropora tenuis & Central GBR & Cantin \& van Oppen (unpubl.) \\
\hline
\end{tabular}

ticulosa, despite initial establishment within larvae. This therefore indicates that the host-symbiont specificity is flexible in this species, at least in the early life history stage. It should be noted that the analysis in this study is unable to verify whether 1 larva hosted 1 or multiple types of Symbiodinium, because all larvae of each aquarium were pooled for DNA analyses. Nonetheless, if the uptake of Symbiodinium types is dependent upon what hosts are exposed to and is fixed at an early age of the host (Little et al. 2004) then primary acquisition by larvae is a critical stage in the entire life history of the host (Baird et al. 2007).

The ecology of free-living Symbiodinium is not well understood, and surveys on the abundance, distribution, motility patterns and diversity of Symbiodinium in the water column and sediment communities are vital. A recent study found sediments to hold a significantly greater abundance of Symbiodinium cells than the water column on the Great Barrier Reef (Littman et al. 2008). However, the migration of Symbiodinium between sediments and the water column could significantly alter the abundance of Symbiodinium in each environment throughout the day, on which there is currently no data. In addition, comparable investigations on primary acquisition in other species of symbiotic invertebrates are needed to determine if similar patterns exist. The roles of freeliving Symbiodinium populations in secondary acquisition should also be examined.

\section{CONCLUSIONS}

Under the wide array of acute environmental and ecological pressures that coral reefs are currently subjected to, coral recruitment and primary acquisition of Symbiodinium by larvae are crucial to the sustainability of this ecosystem. Initiation of host-Symbiodinium association in early life stages and re-establishment of this symbiosis after bleaching events cannot happen without healthy and diverse populations of free-living Symbiodinium. The sediment substrate environment of coral reefs is often overlooked. However, our tank experiment showed that the sediment-associated Symbiodinium are acquired by asymbiotic coral larvae earlier and in more abundance than the Symbiodinium residing in the water column. Our results emphasize the importance of the sediment substrate for supporting resident pools of Symbiodinium that are crucial for establishing symbiosis with invertebrate hosts. Further understanding of the ecology and diversity of free-living Symbiodinium in reef ecosystems and surrounding areas that might represent source populations for them is vital to future management of coral reefs.

Acknowledgements. This research was conducted during the 2007 Center of Excellence International Summer Program held at Sesoko Station, June to August 2007, and was supported by Hawai'i Sea Grant (publication number OP-08-09), the National Science Foundation East Asia Program of Summer Institutes, Japan Society for the Promotion of Science 
Summer Program, and the 21st Century Center of Excellence program of the University of the Ryukyus. Thanks to K. Iwao and $\mathrm{H}$. Taniguchi for collecting and rearing Acropora monticulosa larvae, Dr. M. Morita for collecting and extracting DNA of adult $A$. monticulosa samples, to all the program lecturers and participants for guidance, and 4 anonymous reviewers for suggestions on improving the manuscript.

\section{LITERATURE CITED}

Altschul SF, Gish W, Miller W, Myers EW, Lipman DJ (1990) Basic logical alignment search tool. J Mol Biol 215:403-410

Ayre DJ, Hughes TP (2000) Genotypic diversity and gene flow in brooding corals along the Great Barrier Reef, Australia. Evolution 4:1590-1605

Baird AH, Cumbo VR, Leggat W, Rodriguez-Lanetty M (2007) Fidelity and flexibility in coral symbioses. Mar Ecol Prog Ser 347:307-309

Berkelmans R, van Oppen MJH (2006) The role of zooxanthellae in the thermal tolerance of corals: a 'nugget of hope' for coral reefs in an era of climate change. Proc $\mathrm{R}$ Soc Lond B Biol Sci 273:2305-2312

Brown BE (1997) Coral bleaching: causes and consequences. Coral Reefs 16:S129-S138

Buddemeier RW, Fautin DG (1993) Coral bleaching as an adaptive mechanism. Bioscience 43:320-325

Carlos AA, Baillie BK, Kawachi M, Maruyama TA (1999) Phylogenetic position of Symbiodinium (Dinophyceae) isolates from Tridacnids (Bivalvia), Cardiids (Bivalvia), a sponge (Porifera), a soft coral (Anthozoa), and a free-living strain. J Phycol 35:1054-1062

Coffroth MA, Lewis CL, Santos SR, Weaver JL (2006) Environmental populations of symbiotic dinoflagellates in the genus Symbiodinium can initiate symbiosis with reef cnidarians. Curr Biol 16:R985-R988

Crafts CB, Tuliszewski JR (1995) Motility rhythms in cultured zooxanthellae isolated from the Scyphomedusa Linuche unguiculata. Bull Mar Sci 56:822-825

Douglas AE (2003) Coral bleaching- how and why? Mar Pollut Bull 46:385-392

Fautin DG, Buddemeier RW (2004) Adaptive bleaching: a general phenomenon. Hydrobiologia 530-531:459-467

Fitt WK (1985) Effect of different strains of zooxanthellae Symbiodinium microadriaticum on growth and survival of their coelenterate and molluscan hosts. Proc 5th Int Coral Reef Congr 6: 131-136

Fitt WK, Trench RK (1983) The relation of diel patterns of cell division to diel patterns of motility in the symbiotic dinoflagellate Symbiodinium microadriaticum Freudenthal in culture. New Phytol 94:421-432

Freudenthal HD (1962) Symbiodinium gen. nov. and Symbiodinium microadriaticum sp. nov., a zooxanthellae: taxonomy, life cycle, and morphology. J Protozool 9:45-52

> Glynn PW (1993) Coral reef bleaching: ecological perspectives. Coral Reefs 12:1-17

> Harii S, Kayanne H, Takigawa H, Hayashibara T, Yamamoto M (2002) Larval survivorship, competency periods and settlement of two brooding corals, Heliopora coerulea and Pocillopora damicornis. Mar Biol 141:39-46

Harrison PL, Wallace CC (1990) Coral reproduction. In: Dubinsky Z (ed) Ecosystems of the world: coral reefs. Elsevier Science, Amsterdam

> Hirose M, Reimer JD, Hidaka M, Suda S (2008) Phylogenetic analyses of potentially free-living Symbiodinium spp. isolated from coral reef sand in Okinawa, Japan. Mar Biol 155:105-112
Hoegh-Guldberg O (1994) Population dynamics of symbiotic zooxanthellae in the coral Pocillopora damicornis exposed to elevated ammonium [ $\left.\left(\mathrm{NH}_{4}\right)_{2} \mathrm{SO}_{4}\right]$ concentrations. Pac Sci 48:263-272

> Hoegh-Guldberg O, Williamson J (1999) Availability of two forms of dissolved nitrogen to the coral Pocillopora damicornis and its symbiotic zooxanthellae. Mar Biol 133:561-570

> Hoegh-Guldberg O, Mumby PJ, Hooten AJ, Steneck RS and others (2007) Coral reefs under rapid climate change and ocean acidification. Science 318:1737-1742

> Kinzie RA III, Chee GS (1979) The effect of different zooxanthellae on the growth of experimentally reinfected hosts. Biol Bull 156:315-327

> Kinzie RA III, Takayama M, Santos SR, Coffroth MA (2001) The adaptive bleaching hypothesis: experimental tests of critical assumptions. Biol Bull 200:51-58

Koike K, Yamashita H, Oh-Uchi A, Tamaki M, Hayashibara T (2007) A quantitative real-time PCR method for monitoring Symbiodinium in the water column. Galaxea JCRS 9: $1-12$

Little AF, van Oppen MJH, Willis BL (2004) Flexibility in algal endosymbioses shapes growth in reef corals. Science 304:1492-1494

Littman RA, van Oppen MJH, Willis BL (2008) Methods for sampling free-living Symbiodinium (zooxanthellae) and their distribution and abundance at Lizard Island (Great Barrier Reef). J Exp Mar Biol Ecol 364:48-53

Manning M, Gates RD (2008) Diversity in populations of freeliving Symbiodinium from a Caribbean and Pacific reef. Limnol Oceanogr 53:1853-1861

Marlow HQ, Martindale MQ (2007) Embryonic development in two species of scleractinian coral embryos: Symbiodinium localization and mode of gastrulation. Evol Dev 9: 355-367

Marubini F, Davies PS (1996) Nitrate increases zooxanthellae population density and reduces skeletogenesis in corals. Mar Biol 127:319-328

Miller K, Mundy C (2003) Rapid settlement in broadcast spawning coral: implications for larval dispersal. Coral Reefs 22:99-106

Muscatine L, Falkowski PG, Dubinsky Z, Cook PA, McCloskey LR (1989) The effect of external nutrient resources on the population dynamics of zooxanthellae in a reef coral. Proc R Soc Lond B Biol Sci 236:311-324

> Nishikawa A, Sakai K (2005) Settlement-competency period of planulae and genetic differentiation of the scleractinian coral Acropora digitifera. Zool Sci 22:391-399

Nishikawa A, Katoh M, Sakai K (2003) Larval settlement rates and gene flow of broadcast-spawning (Acropora tenuis) and planula-brooding (Stylophora pistillata) corals. Mar Ecol Prog Ser 256:87-97

> Nozawa Y, Harrison PL (2005) Temporal settlement patterns of larvae of the broadcast spawning reef coral Favites chinensis and the broadcast spawning and brooding reef coral Goniastrea aspera from Okinawa, Japan. Coral Reefs 24:274-282

Palumbi S, Martin A, Romano S, McMillan WO, Stice L, Grabowski G (1991) The simple fool's guide to PCR. Version 2.0. Dept. of Zoology and Kewalo Marine Laboratory, University of Hawaii, Honolulu, HI

> Pochon X, Pawlowski J, Zaninetti L, Rowan R (2001) High genetic diversity and relative specificity among Symbiodinium-like endosymbiotic dinoflagellates of sortid foraminiferans. Mar Biol 139:1069-1078

Pochon X, Montoya-Burgos JI, Stadelmann B, Pawlowski J (2006) Molecular phylogeny, evolutionary rates, and divergence timing of the symbiotic dinoflagellate genus 
Symbiodinium. Mol Phylogenet Evol 38:20-30

Porto I, Granados C, Restrepo JC, Sanchez JA (2008) Macroalgal-associated dinoflagellates belonging to the genus Symbiodinium in Caribbean reefs. PLoS One 3:e2160

Rodriguez-Lanetty M, Krupp DA, Weis VM (2004) Distinct ITS types of Symbiodinium in clade C correlate with cnidarian/dinoflagellate specificity during onset of symbiosis. Mar Ecol Prog Ser 275:97-102

Sampayo EM, Franceschinis L, Hoegh-Guldberg O, Dove S (2007) Niche partitioning of closely related symbiotic dinoflagellates. Mol Ecol 16:3721-3733

Santos SR, Gutierrez-Rodriguez C, Coffroth MA (2003) Phylogenetic identification of symbiotic dinoflagellates via length heteroplasmy in Domain V of chloroplast large subunit (cp23S)-Ribosomal DNA sequences. Mar Biotechnol 5:130-140

Schwarz JA, Krupp DA, Weis VM (1999) Late larval development and onset of symbiosis in the scleractinian coral Fungia scutaria. Biol Bull 196:70-79

Editorial responsibility: Peter Edmunds,

Northridge, California, USA
Stat M, Morris E, Gates RD (2008) Functional diversity in coral-dinoflagellate symbiosis. Proc Natl Acad Sci USA 105:9256-9261

Takabayashi M, Carter DA, Lopez JV, Hoegh-Guldberg O (2003) Genetic variation of the scleractinian coral Stylophora pistillata, from western Pacific reefs. Coral Reefs 22:17-22

Toller WW, Rowan R, Knowlton N (2001) Zooxanthellae of the Montastraea annularis species complex: patterns of distribution of four taxa of Symbiodinium on different reefs and across depths. Biol Bull 201:360-373

Weis VM, Reynolds WS, deBoer MD, Krupp DA (2001) Hostsymbiont specificity during onset of symbiosis between the dinoflagellates Symbiodinium spp. and planula larvae of the scleractinian coral Fungia scutaria. Coral Reefs 20: 301-308

Yacobovitch T, Benayahu Y, Weis VM (2004) Motility of zooxanthellae isolated from the Red Sea soft coral Heteroxenia fuscescens (Cnidaria). J Exp Mar Biol Ecol 298:35-48

Submitted: May 7, 2008; Accepted: November 18, 2006 Proofs received from author(s): January 6, 2009 